\title{
O EMPRESARIAMENTO EDUCACIONAL BRASILEIRO: EXPANSÃO PRIVADO-MERCANTIL DO ENSINO SUPERIOR
}

\author{
The brazilian educational entrepreneurship: private-mercantile \\ expansion of higher education
}

Resumo O presente trabalho busca analisar o movimento conjuntural da mercadorização do ensino superior brasileiro. Os fenômenos recentes que dinamizam a lógica do tratamento do ensino superior como um negócio a ser comercializado no mercado educacional se realizam a partir de fundos de private equity nacional e transnacionais. Constata-se que, especialmente pós-LDB, a dinâmica em processo na mercadorização da educação superior tem contribuído significativamente para o setor privado-mercantil. A configuração hodierna da educação superior denota duas tendências cruciais: i) a concentração de capitais, isto é, constituição de oligopólios educacionais geridos por fundos de investimentos nacionais e transnacionais; ii) as empresas educacionais deixaram de ser de natureza familiar para serem grupos controlados pelo capital financeiro.

Palavras-chave: Educação superior. Empresariamento educacional. Expansão privado-mercantil.

ABSTRACT This study aims to analyze the cyclical movement of the commodification of higher education in Brazil. Recent phenomena that streamline the logic of higher education treatment as a business to be marketed in the educational market are made from national and transnational private equity funds. It appears that, especially after LDB, the dynamics in the process of higher education commodification has contributed significantly to the private-sector market. Today's setting of higher education denotes two key trends: i) the concentration of capital, that is, establishment of educational oligopolies managed by national and transnational investment funds; ii) educational companies are no longer family-owned groups to be controlled by finance capital.

KEY-WORDS: HIGHER EDUCATION. EDUCATIONAL ENTREPRENEURSHIP. PRIVATE-MARKET EXPANSION.

\section{INTRODUÇÃO}

A educação superior vem sendo tratada como objeto de várias investigações em âmbito nacional e internacional no tocante à sua operacionalidade, bem como, às políticas públicas que a ela são direcionadas. O Grupo de Trabalho 11, da Associação Nacional de Pesquisadores em Educação (ANPED), vem desempe-

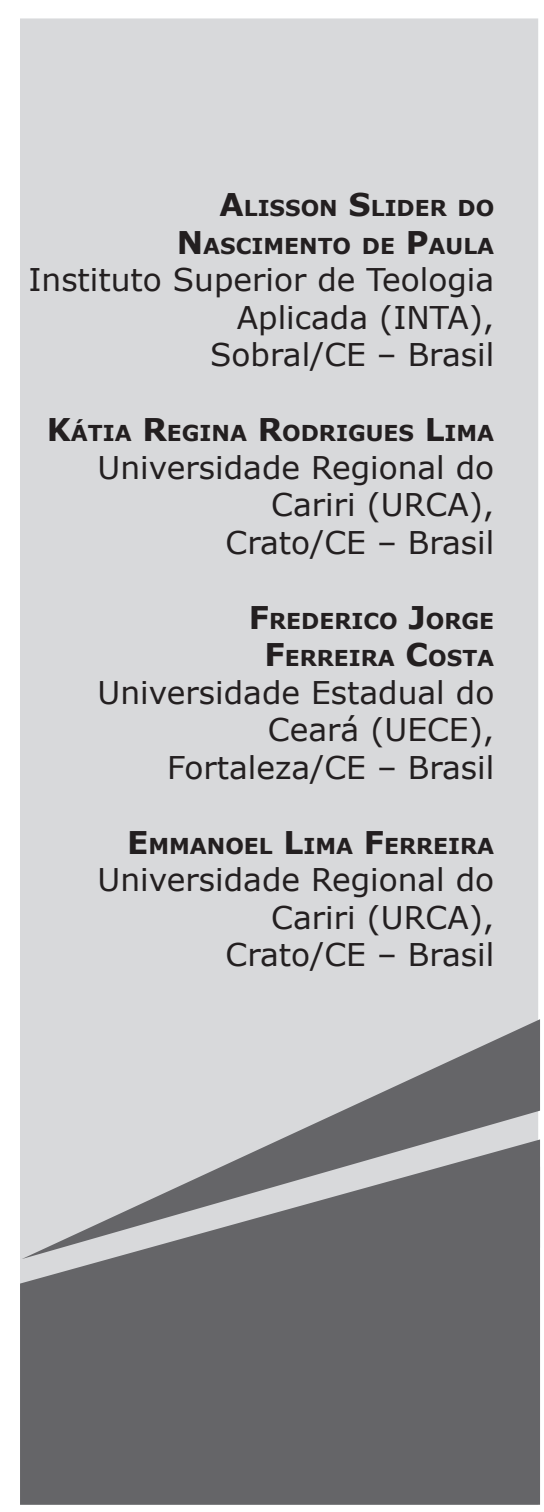


nhando um forte trabalho no que se refere em verificar os elementos mais essenciais do ensino superior em suas esferas público e privada. Nesse percurso, os fenômenos recentes habitam a lógica do tratamento do ensino superior como um negócio a ser comercializado no mercado educacional a partir de fundos de private equity nacional e transnacionais.

Além dos mecanismos do mercado para transformar a educação superior em um nicho de mercado rentável, é necessário a atuação do Estado na garantia da manutenção de sua operacionalidade, que se efetua na constituição de um aparato jurídico além de políticas que subsidiem as instituições privado-mercantis. Esse processo polariza a relação entre o público e o privado, engendrando uma tensão entre esses conceitos, haja vista a necessidade da diluição de suas fronteiras para a extração de lucros pelo setor empresarial do ensino. Essa processualidade não é um caso isolado peculiar do Brasil, logo, trata-se de uma dinâmica da política global acerca da educação superior para as nações periféricas e semiperiféricas do capitalismo.

Desse modo, a partir dos anos 1990, após a implementação da Constituição Federal, em 1988, houve a aprovação da nova Lei de Diretrizes e Bases da Educação Nacional, em 1996, sendo implantados mecanismos orientados pelo Consenso de Washington (CHAVES; AMARAL, 2015). No âmbito da educação superior, uma miríade de mecanismos é posta em operação tendo em vista atender aos anseios do capital, no que diz respeito à diferenciação institucional e das fontes de manutenção, além da grande expansão do setor privado e a legalização das instituições privadas mercantis. Doravante, na primeira década do século XXI, é realizada uma nova forma de se operar a mercadorização ${ }^{1}$ da educação superior no Brasil.

\footnotetext{
Utilizamos o termo mercadorização por compreendermos como um modo de liberalização da oferta de ensino que pode se efetuar de várias formas: privatização direta, expansão do ensino superior privado/mercantil, estímulo à competição, indicadores (rankings), desresponsabilização do Estado, criação de Parceiras-Público-Privado (PPP) entre outros (DALE, 2014).
}

O objetivo do presente trabalho consiste em empreender uma análise acerca do movimento conjuntural da mercadorização do ensino superior brasileiro. Para tanto, discutiremos, num primeiro momento, a polarização entre o público e o privado, buscando desvelar os reais interesses dos setores hegemônicos com essa tensão, além da importância da própria LDB 9.394/06 que engendrou grandes implicações no período após sua promulgação; por conseguinte, discutiremos a dinâmica que se opera no setor privado-mercantil da educação superior brasileira, na consolidação da educação-mercadoria e suas implicações na expansão das instituições de ensino superior privadas, além da massificação das matrículas, dando ênfase nos programas, bem como na inovação do modo de ser da mercadorização do ensino.

\section{TENSÕes entre O público e o privado/ MERCANTIL NO ENSINO SUPERIOR}

Nas várias fases da história da humanidade, o público e o privado têm permeado com uma multiplicidade de significados todos os espaços da vida social. Concordando com Chaves (2006, p. 2), "público e privado são duas esferas distintas que compõem a estrutura social". O público e o privado em função de expressarem significados diversos, bem como opostos, necessitam, desse modo, que seja situada a dimensão na qual está sendo referenciada.

Sustentaremos, neste trabalho, uma concepção calcada na tradição marxiana e engelsiana de Estado, logo, o método analítico selecionado trata-se do materialismo histórico-dialético. Nesse sentido, para obtermos compreensão do significado que permeia os conceitos de público e privado, será preciso partir de uma sintética historicidade, haja vista o pensamento marxiano compreender os fenômenos particulares como parte de um todo, isto é, de uma totalidade.

O Estado trata-se de uma instituição que surge como produto das relações de classes, nas quais suas bases se assentam nas relações de produção, propiciando uma operaciona- 
lidade contraditória no desenvolvimento da sociedade civil. Engels (1964, p. 135-136), esclarece que:

O Estado não é pois, de modo algum, um poder que se impôs à sociedade de fora para dentro; tampouco é a "realidade da ideia moral", nem "a imagem e a realidade da razão", como afirma Hegel. É antes um produto da sociedade, quando esta cega a um determinado grau de desenvolvimento; é a confissão de que essa sociedade se enredou numa irremediável contradição com ela própria e está dividida por antagonismos irreconciliáveis que não consegue conjurar. Mas para que esses antagonismos, essas classes com interesses econômicos colidentes não se devorem e não consumam a sociedade numa luta estéril, faz-se necessário um poder colocado aparentemente por cima da sociedade, chamado a amortecer o choque e mantê-lo dentro dos limites da "ordem". Este poder, nascido da sociedade, mas posto acima dela se distanciando cada vez mais, é o Estado.

Nessa acepção, o Estado surge, portanto, como instituição direcionada à conservação dessa civilização contraditória, levantada sobre conflitos irreconciliáveis. Por seu turno, essa instituição busca assegurar a propriedade privada (MINTO, 2006). Em acréscimo, no Manifesto do partido comunista, Marx e Engels (2010, p. 25) alegam que o poder político do Estado trata-se de um instrumento crucial para uma sociedade construída sobre antagonismos de classe e que se baseia no "poder organizado de uma classe para a opressão de outra”.

Em A ideologia Alemã, os autores supracitados destacam a natureza do Estado, apoderado pela classe burguesa hegemônica, na qual mistifica os interesses de classe. Para
Minto (2006, p. 27), "no momento em que a divisão social do trabalho já se encontra amplamente desenvolvida", a oposição existente entre os interesses particulares e coletivos torna-se notória: "o interesse individual deixa de identificar-se com o interesse coletivo, estranhando-o". No limite, "o interesse geral, que aparece como 'estranho' aos indivíduos, como 'independente' deles, entretanto transfigura-se na forma ilusória necessária a esse tipo de organização social". Assim, Marx e Engels consideram que:

[...] a luta prática destes interesses particulares, que constantemente e de modo real chocam-se com os interesses coletivos e ilusoriamente tidos como coletivos, torna necessário o controle e a intervenção prática através do ilusório interesse "geral" como Estado (1984, p. 49).

Destarte, parece-nos que o Estado caracterizado como local para a conciliação de classes está baseado num disfarce que oculta sua essência de estrutura de dominação. Nesse itinerário analítico, no contexto do sociometabolismo do capital, consideramos o Estado como promotor da esfera pública e o mercado como local da esfera privada. Nesse sentido, a privatização do setor público se realiza no momento em que a esfera privada ocupa a dimensão pública e seus interesses se sobrepõem aos interesses coletivos.

Nessa acepção, o Estado se funda entre o público e o privado, entre o interesse geral e o particular. Contudo, ainda que o poder estatal esteja sendo orientado pelos setores hegemônicos, o Estado não poderia ser somente a expressão de tais interesses. Isto é:

[...] o poder estatal "nem paira sobre a 'sociedade civil', nem exprime a 'vontade geral"', mas varia conforme a conjugação das forças políticas e econômicas de cada momento histórico. Em razão da necessidade de manter o poder 
econômico (apropriação) e político (dominação) da classe que representa, o poder estatal tem de aparecer como representante de certos interesses da classe trabaIhadora (IANI apud MINTO, 2006, p. 34).

Portanto, o Estado que está fundado sobre relações contraditórias é ensejado pelo sociometabolismo do capital a uma aparente autonomia relativa que garante essas relações. Com isso, é um reflexo próprio dos setores hegemônicos que o Estado represente os interesses das camadas populares, ainda que minimamente, conditio sine qua non da própria existência do Estado capitalista, logo, a erradicação da classe trabalhadora em nada positivo contribuiria aos setores hegemônicos, apenas a deflagração de sua ruína. Sendo assim, o Estado, ao garantir o bem público, garante, por seu turno, no aspecto político, jurídico e ideológico, "a exploração do capital sobre o trabalho, a exploração de uma classe minoritária sobre a outra majoritária" (MINTO, 2006, p. 37). No limite, de acordo com Mészáros (2002, p. 106-107), a “formação do Estado moderno é uma exigência absoluta para assegurar e proteger permanentemente a produtividade do sistema do capital".

No que tange ao ensino superior, o Banco Mundial publicou, em 1998, o documento: The financing and management of higher education. A status reporto in wolrdwide reform. Esse documento ressalta o ensino superior antes como bem privado que público. De acordo com o conteúdo do documento, o ensino superior possui características de um bem privado, assim, sendo possível subordinar-se à dinâmica do mercado. Esse argumento está fundado num primeiro momento a partir da compreensão que a educação superior não pode ser considerada um bem estritamente público em função de suas condições de "competitividade (oferta limitada), exclusibilidade (seguidamente se pode obtê-lo mediante pagamento) e recusa (não é reque- rido por todos), todas as características que não respondem às de um bem estritamente público, mas, sim, às de um bem privado". Num segundo momento, "os consumidores do ensino superior estão razoavelmente bem informados e os provedores frequentemente estão mal informados - condições ideais para o funcionamento das forças do mercados" (JOHNSTONE apud SGUISSARDI, 2006).

O debate da educação superior como bem público ou privado é estimulado a partir da proposta da Agenda do Acordo Geral sobre Comércio e Serviços (AGCS) da Organização Mundial do Comércio (OMC) de liberalização dos serviços educacionais. O AGCS alega cobrir e regular todos os tipos de serviços, incluindo a educação. Nesse documento, é exposto o caminho que guia o Acordo Geral sobre Tarifas e Comércio (AGTT) à OMC e ao AGCS; os quatro meios previstos no AGCS para a comercialização da educação; a vinculação do mercado educacional com a OMC; a efervescência do mercado da educação superior; elementos acerca do financiamento, os desafios que são postos para a educação pública, incluindo um anexo com os "Serviços de educação segundo as diretrizes para o estabelecimento das listas nos marcos do AGCS" (SGUISSARDI, 2006, p. 111).

Esse cenário, contudo, não veio a calhar em 1998, em Paris, pois os reitores e acadêmicos ibero-americanos, reunidos na Conferência Mundial do Ensino Superior, alertaram sobre o caráter nocivo das políticas orientadas pelo AGCS, requerendo, assim, que os governos de seus respectivos países que "não se subscrevam compromissos nessa matéria no contexto do Acordo Geral sobre Comércios e Serviços (GATS) da OMC" (CARTA DE PORTO ALEGRE, 2002). Nesse sentido, a despeito da rejeição do AGCS/OMC, as orientações dos organismos internacionais (Banco Mundial, UNESCO e OMC) para a educação superior dos países da periferia capitalista, no que toca a temas referentes à diversificação institucional e dos cursos, das fontes de recursos, foram, em grandes proporções, aderidas e incorporadas no modus operandi das universidades públicas, bem como, na 
política de educação superior brasileira. ${ }^{2}$

É lícito acrescentar a polêmica da polarização explorada com propriedade pelo sociólogo Emir Sader (2003) acerca da contraposição estatal/público x privado/mercantil. $\mathrm{O}$ autor compreende que um dos êxitos teóricos e políticos do neoliberalismo foi ter instaurado uma grande tensão em volta do estatal e privado. O discurso neoliberal, ao dar ênfase em opor o estatal ao privado, tende a favorecer o mercado capitalista, logo, essa contraposição possibilita a desqualificação do estatal excluindo desse debate o público.

Sguissardi (2006, p. 120) contribui para o debate enfatizando que a desqualificação do estatal e valorização do privado se dá com a "caracterização do estatal - como 'ineficiente', 'burocrático', 'corrupto', 'opressor', cavador de impostos e mau prestador de serviços - e o privado - como 'espaço de liberdade individual, de criação, imaginação, dinamismo"'. Nesse itinerário, verifica-se o processo de privatização do Estado que se efetua em virtude de sua contínua desqualificação. Ora, essa privatização é nítida até para o mais míope quando se vê um Estado que transfere estrondosos fluxos de recursos públicos para o setor financeiro, pagando os títulos, amortização e refinanciamento da dívida pública em detrimento de serviços sociais básicos como saúde e educação. Destarte, a redução ao debate entre estatal e privado tenta transformá-los em dois polos, contudo, consoante Sader (2003, p. 3), "o estatal não é um polo, mas um campo de disputa, que nos nossos tempos é hegemonizado pelos interesses privados". Com isso, fica claro que o privado não representa os interesses dos indivíduos, todavia, mercantis, a privatização do Estado se realiza por meio da desestatização em benefício das corporações transnacionais.

\footnotetext{
Desde a década de 1980 os organismos internacionais, em especial o Banco Mundial, têm publicado documentos que se tratam de diretrizes e orientações para a política educacional no países periféricos e semiperiféricos da economia mundial. Indicamos os estudos de Barreto e Leher (2008); Sguissardi (2006); Lima (2011), que contribuem para o debate acerca desse tema.
}

A privatização estatal é constatada quando se verifica as políticas econômicas implementadas desde a década de 1990, tendo como alvos as empresas estatais. Desse modo, essa tensão se realiza, em verdade, não entre estatal $x$ privado, mas entre público $x$ mercantil. É nesse cenário que se realiza, inclusive, a privatização interna das IES públicas, que podem ser privatizadas pelas "diferentes formas de administração e financiamento, autonomia/heteronomia, avaliação/accountability, produção e transmissão do conhecimento, pode estar sendo conduzida e situar-se no espaço do privado/mercantil" (SGUISSARDI, 2003, p. 121). Todavia, além da privatização interna das IES públicas, o Estado possibilita o setor privado-mercantil se expandir em território nacional, além de conceder subsídios financeiros aos seus estabelecimentos.

Nesse sentido, conforme Chaves (2006, p. 6), compreendemos que "a privatização da educação superior não é um fenômeno isolado da dinâmica da estrutura social capitalista". Dando enfoque ao cenário brasileiro, as Instituições Privadas de Educação Superior (IPES) começaram a obter predomínio a partir da reforma universitária de 1968 empreendida pelo governo civil-militar fomentando, portanto, a criação e manutenção de estabelecimentos isolados. Naquele contexto, o setor privado era constituído por um conjunto de instituições comunitárias e confessionais, e como não havia sustentação legal para a existência de empresas educacionais, todas essas instituições foram classificadas como sem fins lucrativos, obtendo, assim, o benefício da renúncia fiscal dos impostos sobre a renda, o patrimônio e os serviços, além da possibilidade de obtenção de recursos do orçamento da união.

No contexto da Constituição de 1934, as instituições educacionais primárias e profissionais se beneficiavam de não pagaram qualquer tipo de tributo. Com a Constituição Federal de 1946, a isenção foi ampliada para todos os tipos de instituições de ensino (CARVALHO, 2013). No conteúdo da redação da Carta Magna de 1988, damos ênfase no: 
Art. 150. Sem prejuízo de outras garantias asseguradas ao contribuinte, é vedado à União, aos Estados, ao Distrito Federal e aos Municípios: $\mathrm{VI}$ - Instituir impostos sobre: [...]

c) patrimônio, renda, ou serviços dos partidos políticos, inclusive suas fundações, das entidades sindicais dos trabalhadores, das instituições de educação e de assistência social, sem fins lucrativos, atendidos os requisitos da lei (BRASIL, 1988).

Para Carvalho (2013, p. 672) "o arcabouço legal ocultou o avanço no crescimento de grandes estabelecimentos mercantis que foram sendo aglutinados e transformados em universidades sem fins lucrativos". Esse cenário teve duração até a promulgação da Lei de Diretrizes e Bases da Educação Nacional (LDB), em 1996, quando estabeleceu-se a existência institucional das instituições de ensino com fins lucrativos.

\section{A POLÍTICA EDUCACIONAL BRASILEIRA Pós-LDB 9.394/96}

O sistema de ensino brasileiro ao longo de sua história vivenciou diversas metamorfoses. A despeito das particularidades da economia brasileira estarem localizadas na periferia da divisão internacional do trabalho, os setores burgueses locais empreenderam um mecanismo legal que sustenta seus interesses, bem como, dos setores hegemônicos internacionais.

Foi no governo Fernando Henrique Cardoso (1994-2002) que Paulo Renato Souza, então ministro da Educação, sancionou em 20 de dezembro de 1996 a Lei de Diretrizes e Bases da Educação Nacional (LDB) sob o $\mathrm{n}^{\circ}$. 9.394/96. Essa lei ficou conhecida como "Lei Darcy Ribeiro", e busca tratar dos caminhos que a educação brasileira deverá seguir ao longo da vigência da LDB.

$O$ processo no Legislativo e Executivo de tramitação dos projetos da LDB no que se refere ao âmbito da sociedade civil, para que fosse tratado o mandado constitucional do art.
22, XXIV, foi polêmico e longo. Diversas foram as mudanças sofridas nos textos que foram feitos desde o começo do processo legislativo por meio de diversas emendas aos projetos. Demasiadas avaliações acerca do texto final da LDB se expressam em uma vasta bibliografia (CATANI; OLIVEIRA, 2000; FRAUCHES, 2000; RISTOF, 2008; BITTAR et al. 2008).

É lícito acrescentar que, além desta bibliografia acerca do tema da LDB, sujeitos coletivos também mostraram pré-disposição em debater esse então novo marco regulatório da educação brasileira. De acordo com Bittar et al.:

Conselho dos Secretários Estaduais de Educação (Consed), o da União dos Dirigentes Municipais de Educação (Undime), o do Fórum dos Conselhos Estaduais de Educação e a da União dos Conselhos Municipais de Educação não só no processo de elaboração como também na efetivação da lei. Muitos outros sujeitos também se puseram a campo a fim de discutir os projetos e sugerir alternativas como é o caso de ocupantes de cargos no aparelho de Estado, associações profissionais de docentes, associações científicas, organizações não-governamentais e pessoas estratégicas (2008, p. 20).

Decorridos vinte anos após a aprovação da LDB 9.394/96, grandes desafios persistem para a educação superior brasileira. Diversas transformações de toda ordem surgiram nesse período, haja vista as políticas de educação que foram orientadas pelo receituário dos organismos internacionais (Banco Mundial, Organização das Nações Unidas para a Educação, Ciência e Cultura - UNESCO, Organização Mundial do Comércio - OMC), nos quais acarretaram um cenário de privatização e elitização do ensino superior. Desse modo, esse nível de ensino continua excludente para os setores das camadas populares. Com efeito, para que se possa analisar esse período é preciso identi- 
ficar as características básicas da educação superior brasileira que, conforme Ristoff (2008, p. 43) são “a) Expansão; b) Privatização; c) Diversificação; d) (entralização; e) Desequilíbrio regional; f) Ampliação do acesso; g) Desequilíbrio de oferta; h) Ociosidade de vagas; i) Corrida por titulação; j) Lento incremento na taxa de escolarização superior".

Ressaltamos que no presente trabalho nos importa tratar especificamente das características a) e b), logo, a despeito da necessidade crucial de análise das demais características, os limites do escopo aqui delimitado não nos permitem ir além das características que tratam da expansão e da privatização.

Sob a orientação do Documento publicado, em 1994, pelo Banco Mundial, Higher education: the lessons of experience, recomendava-se uma maior diversificação das instituições e dos cursos, além de suas fontes de financiamento, sugerindo, desse modo, a manutenção da educação, entre outras coisas, com o pagamento de taxas pelo discente das Instituições de Ensino Superior (IES) públicas.
Esse documento considerava o modelo humboldtiano de universidade inadequado, bem como muito caro para os países periféricos e semiperiféricos, propondo a substituição por um modelo de universidade de ensino (sem pesquisa). O mesmo documento orientava as autoridades a ficarem "alertas aos sinais do mercado". Nessa acepção, a LDB surge como um respaldo jurídico que sustentasse essas orientações, possibilitando a abertura de vários decretos calcados nessas recomendações. De acordo com Sguissardi (2008), sobressai-se o Decreto $n^{\circ}$. 2.306/97, no qual reconhece a educação como um serviço comercializável, em outras palavras, objeto de extração lucrativa.

Nessa perspectiva, a educação superior sofre um processo de expansão. Essa expansão não deve ser confundida com democratização, logo, expressa-se por meio do crescimento das Instituições Privadas de Educação Superior (IPES), a Tabela 1 nos mostra que nos vinte anos de vigência de LDB houve uma considerável expansão do ensino superior:

Tabela 1 - Evolução do número de Instituições de Educação Superior por categoria administrativa - (2003-2014)

\begin{tabular}{c|c|c|c}
\hline \multirow{2}{*}{ Ano } & \multicolumn{3}{|c}{ Instituições } \\
\cline { 2 - 4 } & Total & Públicas & Privadas \\
\hline 2003 & 1.859 & 207 & 1.652 \\
\hline 2004 & 2.013 & 224 & 1.789 \\
\hline 2005 & 2.165 & 231 & 1.934 \\
\hline 2006 & 2.270 & 248 & 2.022 \\
\hline 2007 & 2.281 & 249 & 2.032 \\
\hline 2008 & 2.252 & 236 & 2.016 \\
\hline 2009 & 2.314 & 245 & 2.069 \\
\hline 2010 & 2.377 & 277 & 2.100 \\
\hline 2011 & 2.365 & 284 & 2.081 \\
\hline 2012 & 2.416 & 304 & 2.112 \\
\hline 2013 & 2.391 & 301 & 2.090 \\
\hline 2014 & 2.368 & 298 & 2.070 \\
\hline$\Delta 2003-2014$ & $27,38 \%$ & $43,96 \%$ & $25,30 \%$ \\
\hline
\end{tabular}

Fonte: Inep/Mec (2010; 2014). Elaboração própria 
A partir dos dados expostos na Tabela 1, constatamos que no período analisado houve um crescimento de $27,38 \%$ de todas as IES no Brasil. Ademais, na quantidade de IES públicas houve um crescimento da ordem dos $43,96 \%$ ao passo que as IPES obtiveram crescimento de apenas $25,30 \%$. Apesar de em termos percentuais as IES públicas terem obtido maior expansão no número de instituições frente às IPES, as últimas, quando comparadas com as IES públicas, possuem montante de instituições bem superior. Em 2014, o Brasil possuía 2.368 IES, sendo públicas 298 e privadas 2.070. As IPES possuem 1.772 instituições a mais, representando a ordem $87,42 \%$ da quantidade total de IES, ao passo que as IES públicas possuem o percentual da ordem dos $12,58 \%$ do total de IES.

Nessa acepção, verificamos que além da expansão da quantidade de IES no Brasil, houve uma predominância das IPES em detrimento das IES públicas. Nesse sentido, verificamos que, além da expansão da quantidade de IES no Brasil, houve uma predominância das IPES em detrimento das IES públicas. Se lançarmos olhos para a expansão de matrículas nas IES segundo sua categoria administrativa é possível verificar a alta escala de ofertas de cursos de graduação e pós-graduação, conforme o Censo da Educação Superior de 2014 elaborado pelo Instituto Nacional de Estudos e Pesquisa Anísio Teixeira (INEP).

Tabela 2 - Estatísticas Básicas da Superior por categoria Administrativa (2014) - Brasil

\begin{tabular}{|c|c|c|c|c|c|c|}
\hline \multirow[t]{3}{*}{ Categorias } & \multicolumn{6}{|c|}{ Categoria Administrativa } \\
\hline & \multirow{2}{*}{$\begin{array}{c}\text { Total Ge- } \\
\text { ral }\end{array}$} & \multicolumn{4}{|c|}{ Pública } & \multirow[t]{2}{*}{ Privada } \\
\hline & & Total & Federal & Estadual & Municipal & \\
\hline \multicolumn{7}{|c|}{ Educação Superior - Graduação } \\
\hline Cursos & 32.878 & 11.036 & 6.177 & 3.781 & 1.078 & 21.842 \\
\hline Matrículas & 7.828 .013 & 1.961 .002 & 1.180 .068 & 615.849 & 165.085 & 5.867 .011 \\
\hline \multicolumn{7}{|c|}{ Educação Superior - Sequencial de Formação Específica } \\
\hline Matrículas & 11.752 & 564 & 137 & 252 & 175 & 11.188 \\
\hline \multicolumn{7}{|c|}{ Educação Superior - Pós-Graduação Stricto Sensu } \\
\hline Matrículas & $299 \cdot 355$ & 251.096 & 170.128 & 79.633 & 1.335 & 48.259 \\
\hline \multicolumn{7}{|c|}{ Educação Superior - Total } \\
\hline $\begin{array}{c}\text { Matrícula } \\
\text { Total }\end{array}$ & 8.139 .120 & 2.212 .662 & 1.350 .333 & 695.734 & 166.595 & 5.926 .458 \\
\hline
\end{tabular}

Fonte: Inep/Mec (2014)

Conforme o informado na Tabela 2, constatamos a assimetria entre as IPES e as IES públicas. No que tange às matrículas na graduação, do total de 7.828.013 matrículas, 1.961 .002 estão concentradas nas IES públicas (25,05\%), ao passo que as IPES possuem 5.867.011 matrículas, referente ao percentual da ordem de $74,95 \%$. No que se refere às matrículas nos cursos sequenciais de formação específica, do total de 11.752 matrículas, as IES públicas possuem 564 do total das matrículas
(4,79\%) enquanto as IPES possuem 11.188 do total matrículas (95,21\%). Nos cursos de pós-graduação stricto sensu, do total de 299.355 matrículas, as IES públicas possuem 251.096 matrículas (83,87\%), ao passo que as IPES detêm apenas 48.259 matrículas (16,13\%). Desse modo, somando o total das matrículas na graduação, cursos sequenciais e pós-graduação stricto sensu, há uma quantidade de 8.139.120 matrículas na educação superior brasileira, sendo que as IES públicas concentram um to- 
tal de 2.212 .662 matrículas (27,18\%), enquanto as IPES concentram um total de 5.926 .458 matrículas (72,82\%).

No que diz respeito aos cursos ofertados, do total de 32.878 cursos de ensino superior, 11.036 cursos são ofertados pelas IES públicas, nos termos percentuais de $33,56 \%$, ao passo que nas IPES, em 2014, foram ofertados 21.842 cursos, $66,44 \%$ do total dos cursos.

Em acréscimo, a partir do exposto é possível afirmar sobre a predominância do setor privado-mercantil do ensino superior, no que toca à quantidade de instituições, bem como, de matrículas. Com a LDB possibilitando a processualidade da mercadorização da educação, compreendemos as severas implicações na formação dos quadros da sociedade a partir de sua formação universitária. Assim, esse cenário sinaliza diretamente para um processo de certificação em alta escala atendendo às demandas do trabalho da mundialização financeira.

\section{A CONSOLIDAÇÃO DO SETOR EMPRESA- RIAL NA CONSTITUIÇÃO DA EDUCAÇÃO- -MERCADORIA}

A educação superior vivenciou significativas mudanças em seu modus operandi no período pós-LDB. Outro fenômeno que também resultou em significativas implicações para a universidade no mesmo período foi a processualidade do ajuste estrutural do aparelho do Estado brasileiro. É lícito ressaltar que esse processo ainda está em curso, contudo, teve início na década de 1990, a partir das orientações dos organismos internacionais como resultado da severa crise da dívida pública eclodida nos países da América Latina em 1982.

Na década de 1990, o Banco Mundial publicou dois documentos com siglas iguais: PREAL. Ambos apontavam para a "necessidade" de reformas - um se tratava do Programa de Reformas do Estado para a América Latina e o outro era o Programa de Reforma da Educação para a América Latina. Para Silva Júnior et al. (2013), esses documentos contribuíram para a mudança na morfologia das universidades enquanto instituições republicanas. Em acréscimo, o centro gravitacional da reforma do aparelho do Estado foi determinado, em 1995 no governo Cardoso, por meio do Plano Diretor da Reforma do Estado, ${ }^{3}$ no qual possuiu como principais diretrizes: "a privatização, a terceirização e a publicização” (CHAVES, 2010, p. 482).

Nesse percurso, a educação superior brasileira começou a se adaptar ao cenário das mudanças socioeconômicas, buscando adequar-se à competitividade e às demandas do mercado. Com efeito, no quadro da atual crise estrutural do sistema sociometabólico do capital, a universidade como lugar da produção do conhecimento científico é transmutada para assumir o papel de desenvolver e tornar competitivo o setor produtivo e as nações periféricas, como condition sine qua non para a concorrência no mercado mundial do capital.

A universidade incorpora função estratégica como instrumento de irradiação ideológica capitalista, bem como nicho mercantilista rentável. Isto se dá em decorrência do reordenamento do processo produtivo consequente da crise do capital, no qual preconiza a necessidade da formação de um perfil de trabalhador de novo tipo, dotado de competências que atendam às demandas do mercado assim como adaptáveis às novas relações contratuais envolvendo capital e trabalho.

Para Chaves et al. (2013, p. 7), "o projeto neoliberal de educação desses organismos internacionais para países periféricos do capital é caracterizado pelo aprofundamento da privatização, pela desnacionalização da educação e consolidação de um novo mercado educativo global". É no contexto da criação de mercados educativos que a educação superior é inserida na condição de serviço comercializável, que permeia a mercantilização e a financeirização desse nível de ensino.

Nessa acepção, concordando com a concepção de Rodrigues (2007), existem dois

\footnotetext{
O Plano Diretor da Reforma do Estado (PDRE) estabelece quais são as responsabilidades diretas do Estado. Conforme o PDRE, o ensino superior público estatal se trata de um serviço não exclusivo do Estado, desse modo, suas instituições deveriam se tornar organizações sociais (BRESSER-PEREIRA, 1997).
} 
modos do capital enxergar a educação: educação-mercadoria e mercadoria-educação. Conforme esse autor: "cada uma dessas perspectivas se liga diretamente à forma como o capital busca a autovalorização e cada uma delas é face de uma mesma moeda, ou seja, são formas sob as quais a mercadoria se materializa no campo da formação humana" (p. 5). A educação-mercadoria corresponde quando o capital busca se valorizar a partir da venda de serviços educacionais, isto é, capital investido em instituições educacionais sendo escola ou IES, esse capital buscará tratar a educação como uma mercadoria no qual a consumação de seu objetivo é a venda no mercado de serviços educacionais. No que se refere à educação superior, esses serviços podem ser compreendidos como cursos de graduação em IPES, bem como, cursos pagos nas IES públicas como o caso das pós-graduações lato sensu. Por seu turno, a mercadoria-educação se realiza quando o conhecimento se trata de um insumo necessário para o processo produtivo, em outras palavras, quando a formação profissional propicia as competências básicas para atender às demandas do mercado de trabalho, assim, realiza-se essa perspectiva.

No presente trabalho, a primeira perspectiva, educação-mercadoria é que possui centralidade no objeto aqui delimitado, portanto, nos deteremos na análise de sua processualidade. Destarte, concernente à educação-mercadoria a venda de um curso de graduação interessa, mormente, à instituição que está comercializando esse curso. No limite, a relação estabelecida nesse processo é entre a oferta e a demanda. A partir dessas premissas, as IES públicas e privadas buscam adequar-se às metamorfoses da mundialização do capital. Esse processo inicia-se ainda na década de 1990.

O Brasil inicia um processo de ajustamento de seu projeto político nacional à nova ordem mundial. Esse movimento, que se acentua sob a liderança de Fernando Henrique
Cardoso, expressar-se-á em todas as esferas da atividade humana, em particular na educação superior, mediante a tentativa de reconfiguração desse espaço social, segundo a ótica e a racionalidade econômicas. O capital procura reconfigurar tal esfera segundo seus objetivos e a sua lógica (SILVA JÚNIOR; SGUISSARDI, 2001, p. 193-194).

Os governos Lula da Silva e Dilma Rousseff, respectivamente, aprofundaram esse cenário de empresariamento da educação superior. As diretrizes centrais da reforma da educação superior implementada por esses governos se trataram da diversificação das instituições, dos cursos e das fontes de financiamento, diretrizes que se afinam com as orientações do Banco Mundial. Em acréscimo, essas diretrizes implicam o aprofundamento da mercantilização da educação superior em dois movimentos: i) a diversificação das instituições e dos cursos se realiza através da liberalização dos serviços educacionais que decorre na expansão das IPES e ii) a diversificação das fontes de financiamento se concretiza a partir da privatização interna das IES públicas que se dá por meio da cobrança de mensalidades pelos cursos pagos, fundações de direito privado, parceria envolvendo universidades e empresas engendrando severas implicações para o tripé indissociável universitário: ensino-pesquisa-extensão.

Os serviços sociais, em especial a educação, estão localizados no setor não exclusivo do Estado, engendrando assim o surgimento de uma nova fração burguesa concentrada no setor de serviços. Essa fração burguesa está diretamente articulada com os serviços de saúde e educação, logo, é determinada pelos condicionantes da realidade concreta sob a égide do ideário neoliberal. Conforme Boito Júnior (apud RODRIGUES, 2007, p. 18), "a nova burguesia de serviços é o carniceiro, o animal que vive das sobras da guerra que o neoliberalismo trava contra os trabalhadores". Portanto, as IPES representam o cresci- 
mento e o fortalecimento dessa nova fração burguesa.

É lícito ressaltar que, a partir do exposto, uma grande quantidade de políticas foi implementada para efetivar e pôr em operacionalidade a educação-mercadoria. A liberalização dos serviços educacionais, o investimento público sendo direcionado para as IPES, recursos privados para as IES públicas, contratos de gestão, entre outros, são elementos que configuram o cenário da contribuição do Estado para os empresários da educação superior e em detrimento da educação superior pública estatal. No limite, as IPES são fomentadas, pelos governos, para se expandirem por meio de isenção fiscal, em especial a venda de cursos aligeirados, flexibilizados e a distância, desarticulados com a pesquisa e centrando-se somente na esfera do ensino.

\section{MASSIFICAÇÃO DO ENSINO SUPERIOR PRIVADO/MERCANTIL E SUA REGULAÇÃO ESTATAL}

Nesta seção, centraremos a nossa análise nas intervenções realizadas pelo Estado diretamente sobre o ensino superior privado-mercantil desvelando, desse modo, sua predominância na oferta desse serviço. O processo de intervenção estatal para as IPES surge a partir da compreensão da educação enquanto um serviço público. Nesse sentido, as IPES ofertando cursos de educação superior estariam, por seu turno, ofertando um serviço público, contudo não-estatal, sendo possível receber financiamento do Estado.

Com efeito, os recursos do orçamento da União para a manutenção do ensino superior brasileiro são direcionados não apenas para as Instituições Federais de Ensino Superior (IFES), mas, também, para as IPES. Todavia, para que fosse exequível essa processualidade, políticas foram implementadas dando consistência na concepção público não-estatal.

Tendo em vista que, a partir das orientações do Banco Mundial para a educação superior da periferia capitalista, esse nível de ensino deve estar passível ao aprofundamento da heteronomia cultural e institucional, assim fincando sob os interesses do setor privado-mercantil. Destarte, com a publicação do documento, em 1994, intitulado: Educação superior: as lições da experiência (BANCO MUNDIAL, 1994), as diretrizes foram apontadas tendo em vista buscar moldar o ensino superior conforme a lógica da divisão internacional do trabalho. Essas diretrizes, que buscam reformular a educação superior da América Latina e Caribe, apresentam quatro estratégias que são os pilares desse documento.

A primeira se refere à necessidade da diversificação das instituições e dos cursos, preconizando, dessa forma, a existência de um cenário com universidades públicas, privadas e instituições não universitárias, incluindo cursos de curta duração e com currículos flexibilizados, cursos politécnicos, a distância e ancorados em ciclos como os que constam no projeto universidade nova.

A segunda estratégia trata da necessidade da diversificação das fontes de financiamento para as IES públicas. Essa estratégia se realiza a partir da oferta de cursos pagos, taxas referentes à mensalidades e matrículas, arrefecimento de financiamento público para atividades que não sejam estritamente relacionadas com educação, além de arrecadação a partir de captação de recursos no setor privado por meio de consultorias e pesquisas, isto é, atividades que se encaixam nos ditos serviços educacionais a serem vendidos para as empresas. Soma-se a isso a parceria com fundações de direito privado que medeiam os convênios entre universidades e empresas, erigindo, assim, uma administração flexibilizada.

Concernente à terceira estratégia, por sua vez, essa busca realçar o debate acerca da necessidade da redefinição das funções do Estado para que seja exequível a privatização da educação. Nesse sentido, faz-se necessário a constituição de aparato político-jurídico - a LDB é um grande exemplo - que atendam qualitativamente aos intentos dessa estratégia. No limite, a quarta estratégia trata da defesa da qualificação da educação superior por meio da eficiência garantida da oferta do 
setor privado-mercantil, de acordo com o próprio documento:

As instituições responsáveis pelos programas avançados de ensino e pesquisa deveriam contar com a orientação de representantes dos setores produtivos. A participação dos representantes do setor privado nos conselhos administrativos das instituições de ensino superior, públicas e privadas, pode contribuir e assegura a adequação dos programas acadêmicos (BANCO MUNDIAL, 1994, p. 6).

Desse modo, damos ênfase na lei $n^{\circ}$. 11.079, de dezembro de 2004, que institui as Parcerias Público-Privadas, na qual demonstra a subserviência do lócus acadêmico aos interesses do capital, consolidando a ampliação do campo de atuação do setor privado-mercantil e na redução do espaço público. Com isso, busca-se naturalizar a partir de aparatos legais a circulação de recursos privados no âmbito público e recursos públicos no âmbito privado.

Com a promulgação da LDB, e a implementação das Parcerias Público-Privadas, aprofundou-se a privatização da educação superior brasileira tanto na expansão quantitativa de instituições privadas, bem como, na privatização interna das universidades públicas estatais. Nesse sentido, são dadas as bases para o aprofundamento do Fundo de Financiamento Estudantil (FIES) e também para a criação do Programa Universidade Para Todos (ProUni). O modus operandi de ambos centra-se na compra de vagas públicas nas IPES, logo, na redefinição do papel do Estado brasileiro a partir de seu ajuste estrutural que se iniciou na década de 1990. Uma instituição privada que oferta um serviço educacional está, por seu turno, ofertando um serviço público não-estatal, assim, podendo receber subsídios financeiros da esfera pública. Desse modo, essa processualidade estaria atendendo positivamente à orientação do Banco Mundial (1997, p. 44) em que ressalta que o
Estado deve fomentar financeiramente as IPES, propiciando, desse modo, "condições de igualdade para todas as instituições de ensino superior, sejam elas públicas ou privadas", além de engendrar um "ambiente positivo" para as IPES.

No que concerne ao ProUni, este programa atendeu aos anseios das instituições de ensino superior filantrópicas, confessionais, comunitárias e com fins-lucrativos. De acordo com o Folha de S. Paulo (2004), o ProUni deveria ter sido lançado em 2003, contudo, houve um adiamento em virtude das reivindicações feitas por reitores das IFES, além dos próprios representantes de associações de entidades privadas de educação superior, os últimos apontaram uma crítica para o quantitativo de vagas fornecidas, em oposição, exigiram isenção do imposto sobre a renda e mais três tributos para as IPES com fins lucrativos. ${ }^{4}$ Nessa acepção, o Projeto de Lei (PL) do ProUni esteve em tramitação no Congresso, assim, o governo Lula da Silva editou, em 10 de setembro de 2004, a Medida Provisório (MP) nº. 213 que instituiu o ProUni. Por conseguinte, o Decreto $n^{\circ}$. 5.245/04 regulamentou a Portaria $\mathrm{n}^{\circ}$. 3.268/04, determinando os meios de adesão das IPES ao ProUni. Em 2005, o ProUni tornou-se lei - Lei $n^{\circ}$. 11.096/05. Com isso, às IPES que aderirem esse programa serão garantidas isenções fiscais de: Imposto de Renda de Pessoa Jurídica; Contribuição Social para Financiamento da Seguridade Social e Contribuição para o Programa de Integração Social (OTRANTO, 2006).

Essas vagas são ofertadas como bolsas integrais ou parciais, tendo como público-alvo egressos de escolas públicas ou mesmo particulares, desde que tenham sido bolsistas com determinado nível de renda familiar. O ProUni é um meio de privatização da educação superior que escamoteia a realidade, logo, se mostra como política social em que exalta a democratização de vagas no ensino superior, ocultando a vasta quantidade de recursos públicos que o Estado deixa de arrecadar

4 A lógica da renúncia fiscal está associada ao ProUni. Para maior aprofundamento, ver Carvalho (2006). 
em função das isenções fiscais das IPES que aderirem ao programa. Nesse cenário de clara evidência da privatização do ensino superior, no qual impulsiona novas formas de valorização do capital, a partir da compreensão desse nível de ensino como nicho mercadológico altamente rentável, compreende-se a realização da educação-mercadoria.

Em acréscimo, faz-se necessário recorrer a dados que possam diagnosticar o montante de recursos que o Estado deixou de arrecadar a partir do ProUni. Para isso, apresentamos na Tabela 3 o gasto tributário da União com o programa em tela.

Tabela 3 - Gasto Tributário da União com o ProUni (2005-2014)

\begin{tabular}{c|c}
\hline Ano & ProUni \\
\hline 2005 & 177.086 .854 \\
\hline 2006 & 343.789 .715 \\
\hline 2007 & 535.882 .639 \\
\hline 2008 & 631.266 .786 \\
\hline 2009 & 735.511 .137 \\
\hline 2010 & 762.939 .552 \\
\hline 2011 & 698.659 .132 \\
\hline 2012 & 890.479 .903 \\
\hline 2013 & 830.190 .930$. \\
\hline 2014 & 625.001 .269 \\
\hline Total & 5.400 .616 .987 \\
\hline
\end{tabular}

Fonte: Secretaria da Receita Federal. Demonstrativo dos Gastos Governamentais Indiretos de Natureza Tributária (Gastos Tributários) - PLOA 2014; Reis (2016)

A partir dos dados expostos na Tabela 3 podemos verificar que, desde a implementação do ProUni, o gasto tributário gerado ultrapassa a ordem dos R\$ 5 bilhões, evidenciando, com isso, um crescimento percentual de $352,93 \%$ dos recursos não arrecadados. Esse gasto tributário injetado se fosse convertido em arrecadação e direcionado para o financiamento das IFES, em grande medida, iria contribuir para a manutenção estrutural dessas instituições, contudo, essa política está ali- nhada com os apontamentos dos organismos internacionais no que se refere aos subsídios públicos destinados às IPES.

O FIES é outra política que suas determinações fundamentais seguem a linha do ProUni. Esse programa foi criado no governo Fernando Henrique Cardoso (FHC) (1995-2002), especificamente em $1999,{ }^{5}$ e sua fonte de financiamento é a mesma do Programa de Crédito Educativo para Crianças Carente (CREDUC), ${ }^{6}$ por meio da Medida Provisória n'. 1.827/99, oficializada pela lei $n^{\circ}$. 10.260/01. O FIES amplia a lógica da privatização da educação superior arrecadando fluxos de recursos dos cofres públicos. Consoante Queiroz (2015, p. 46):

O financiamento destina-se aos estudantes matriculados em cursos da educação profissional e tecnológica, bem como em programas de mestrado, mestrado profissional e doutorado, para os quais serão financiados até $100 \%$ dos encargos educacionais cobrados dos estudantes pelas IES privadas. No CREDUC, as IES recebiam em espécie, já no FIES [...] essas instituições recebem títulos do Tesouro Nacional, que podem ser trocados por dinheiro ou usados para pagar o Instituto Nacional de Seguridade Nacional (INSS).

O FIES passou por inovações ao longo do governo Lula da Silva. A partir da Portaria Normativa $\mathrm{n}^{\circ}$. 02, de 31 de março de 2008, articula a distribuição dos recursos do FIES com oferta de bolsas parciais do ProUni. Nesse

5 Nesse período, o FIES foi criado a partir da MP $\mathrm{n}^{\circ}$. 1.827 , de 27 de maio de 1999, sendo, por seu turno, regulado pelas Portarias $M E C n^{\circ} .860$, de 27 de maio de 1999, e 1.386, de 15 de setembro de 1999, além de haver reedições. É lícito acrescentar que as verbas do FIES são oriundas, conforme Queiroz (2015, p. 55) “de dotação orçamentária do MEC, retorno de financiamento e recursos de loterias não utilizados pelo antigo Programa de Crédito Educativo - PCE".

6 O governo Collor de Mello, em 25 de junho de 1992, implementou o Programa Educativo para Estudantes Carentes (CREDUC). 
sentido, para o estudante que conseguir apenas bolsa parcial (50\%), poderá obter o restante do financiamento por meio do FIES.

No governo Lula da Silva, o FIES passou por mudanças buscando seu aprimoramento normativo e operacional por meio da lei $n^{\circ}$. 12.202/10. Essas mudanças contribuíram para a privatização do ensino superior e o setor empresarial. Segundo Vila et al. (2012):

A expansão do setor privado mercantil do ensino superior foi reforçada pelas políticas educacionais ensejadas nos dois governos Lula e ampliadas no governo Dilma, como é o caso do Programa Universidade para Todos (PROUNI) e seus sucessivos reajustes, no sentido de ampliar a oferta e suprir as demandas do empresariamento da educação superior; do Fundo de Financiamento ao Estudos de Ensino Superior (FIES); da abertura do setor educacional para a participação das empresas e grupos estrangeiros; e da utilização do ensino a distância (EaD) como via para a democratização do acesso à educação, dentre outros mecanismos (p. 169).

O FIES alinha-se com o discurso da democratização do acesso ao ensino superior, seguindo, assim, o mesmo fio ideológico do ProUni, financiamento público nas IPES, dissolvendo as fronteiras entre o público e o privado. No que se refere aos empréstimos realizados pelo governo federal para o funcionamento do FIES, os dados da Tabela 4 expõem a evolução das verbas públicas injetadas nas IPES.

Conforme o período analisado (20032014), é possível perceber que o total de recursos públicos injetados no FIES supera a ordem dos $\mathrm{R} \$ 47$ bilhões de reais, contendo uma evolução percentual de $833,84 \%$ nas despesas da União com o FIES. Além disso, se focarmos nos últimos dois anos de análise (2013-2014), é evidenciado o aumento nos subsídios para o programa. No limite, o FIES tem contribuído para o setor privado-mercantil do ensino superior. "Com a injeção de recursos do FIES, as IES privadas têm garantido o pagamento das mensalidades de uma grande parcela de estudantes, o que favorece a expansão desse setor" (CHAVES, 2015, p. 438).

Tabela 4 - Evolução dos empréstimos do FIES (2003-2014)

\begin{tabular}{|c|c|}
\hline \multicolumn{1}{|c|}{ Ano } & FIES \\
\hline 2003 & 1.341 .626 .724 \\
\hline 2004 & 1.237 .629 .607 \\
\hline 2005 & 1.305 .932 .989 \\
\hline 2006 & 1.455 .157 .896 \\
\hline 2007 & 1.490 .535 .757 \\
\hline 2008 & 1.699 .753 .769 \\
\hline 2009 & 2.276 .285 .230 \\
\hline 2010 & 3.052 .490 .346 \\
\hline 2011 & 3.962 .044 .038 \\
\hline 2012 & 8.372 .431 .851 \\
\hline 2013 & 12.528 .635 .389 \\
\hline 2014 & $833,84 \%$ \\
\hline $2003-2014$ &
\end{tabular}

Fonte: Portal Orçamento - Senado Federal (2014); Reis (2016)

Essa lógica é aprofundada com a instituição do Plano Nacional de Educação (PNE - 2014-2024), no qual em suas metas e estratégias para a educação superior busca manter e aprofundar as políticas e diretrizes que contribuem, em grande proporção, para a expansão do setor privado-mercantil, além de precarizar ainda mais as IES públicas com a concepção de continuidade de programas como o REUNI.?

\footnotetext{
Programa de Apoio a Planos de Reestruturação e Expansão das Universidades Federais (REUNI), instituídos pelo Decreto $n^{\circ}$. 6.096/07. No PNE (2014-2024), esse programa ganha nova roupagem deixando de ser uma política de governo para uma política de Estado.
} 
A expressão do modus operandi da mercadorização do ensino superior no século XXI - a predominância dos fundos de investimento e a inserção na bolsa de valores

O atual modo de organização da economia global se dá por meio da mundialização financeira. Essa lógica acarreta grandes modificações na operacionalidade do campo educacional privado. A expansão colossal das IPES no Brasil, conforme Chaves (2010, p. 495), "se deu a partir do discurso prepotente de que o mercado é bom empreendedor e que a privatização deve ser o dogma central a ser adotado". Em acréscimo, o cenário da educação superior privada brasileira passou por grandes metamorfoses no decurso de uma década, na qual se destaca o controle dos fundos de investimentos nacionais e transnacionais que agem no mercado do ensino superior privado. Essas metamorfoses não se circunscrevem ao domínio acionário de universidades, faculdades e centros universitários, logo, no modus operandi hodierno, o capital financeiro necessita de taxas de lucratividades que apenas são factíveis por meio da atuação do Estado.

Com a edição dos Decretos - 2.207/97 e 2.306/98 - é legalizado a educação ser tratada como mercadoria. Esses Decretos impulsionaram uma distinta dinâmica no que tange à mudança estatuária e do regime administrativo das IPES a partir de 1997, conforme Sguissardi (2015, p. 874), em 1999 "as IES particulares, com fins lucrativos, já eram $58 \%$ do total de 905 IES privadas ou $48 \%$ do total de 1.097 [...] em 2010, as IES privadas particulares ou privado-mercantis já eram $77,8 \%$ e, hoje, possivelmente ultrapassem $80 \%$ das cerca de 2.400 IES do país".

Consideramos que a partir de 2007 o processo de mercadorização da educação superior incorpora uma nova natureza quando surge um movimento significativo de incorporações e fusões de empresas educacionais. Os grandes grupos educacionais se destacam, estes se tratavam de empresas de famílias e passam a serem controladas por fundos de private equity, assim, esses grupos abandonam o verniz da filantropia e assumem publicamente interesses lucrativos.
No período entre 2007 e 2014 ocorrem aproximadamente 156 fusões de instituições, na primeira fase deste novo momento do processo de mercantilização. A partir de 2013 e autorizado em 2014, observa-se um segundo momento que se relaciona com as fusões de grandes conglomerados, como o foi o caso Kroton/Anhanguera, que na época criou uma empresa com valor de mercado de $\mathrm{R} \$ 24$ bilhões de reais, segundo revistas especializadas como a Exame e Valor Econômico, tal como a fusão entre o grupo Estácio Participações e a Uniseb. Ambas fusões foram autorizadas posteriormente pelo Conselho Administrativo de Defesa Econômica (CADE), da Presidência da República, confirmando a educação como uma fronteira de acumulação do capital. Por último, ainda é preciso destacar o papel que cumprem o Banco Nacional do Desenvolvimento Econômico e Social (BNDES), conforme consta no Edital de 2009, que estabeleceu o Programa Melhoria do Ensino das Instituições de Ensino Superior (Programa IES) destina ao financiamento do setor privado e que já reconhecia a existência de uma nova fase da mercantilização, ao destacar as IES que estariam em claro processo de reestruturação financeira, o que parece confirmar a hipótese de que o Estado assume papel importante e impulsiona, o processo de monopolização do setor (LEHER; SOUSA, 2016, p. 3).

Nessa acepção, sob o véu da mercadorização do ensino superior, buscando atender aos anseios do capital financeiro internacional, surge, em fevereiro de 2007, uma nova forma de se operar a mercadorização da educação superior, quando as IPES vão à bolsa de valores. Nesse ano, houve a abertura de capital e a oferta pública inicial, ou seja, lançaram ativos no mercado de ações subsidiadas por fundos de investimento nacionais 
e transnacionais, a Anhanguera Educacional na Bolsa de Valores de São Paulo (Bovespa), sendo que a Estácio de Sá, Kroton Educacional, do Grupo Pitágoras e a Sociedade Educação Brasileira (SEB), controlada do COC, seguiram a mesma trilha. De acordo com a informação publicada no Retratos do Brasil, as vendas de ações dessas instituições, juntas, conseguiram captar $\mathrm{R} \$ 1,9$ bilhão, entre 2007 e 2008, sendo que muitos de seus compradores foram grupos estrangeiros (RELATOS DO BRASIL apud OLIVEIRA, 2009).

O movimento da oferta de ativos na Bovespa mostra-se essencial para os interesses do capital. Conforme demonstra Sguissardi (2015), de 2012 a 2014 o setor da educação superior privada no mercado de ações tem se mostrado demasiadamente promissor, pois entre 16 setores da economia presentes na Bovespa foi o setor mais lucrativo, entre agosto de 2012 a agosto de 2014 "enquanto o Ibovespa [...] teve uma redução de $3,67 \%$; a Vale (VALE 5), redução de 13,48\%; e a Petrobras (PETR4), valorização de 9,32\% de suas ações, a Kroton (KROT3) teve valorização de $324 \%$ e a Estácio (ESTC3), 240,97\% de suas respectivas ações" (p. 870).

Esse tipo de transação demonstra o novo patamar em que se opera a mercadorização da educação superior com fins lucrativos, em especial as controladas por fundos de private equity ou por ativos na Bovespa. No que se refere ao cenário global, conforme Savage (apud OLIVEIRA, 2009), o setor internacional de educação movimenta por ano US\$ 2,2 trilhões, 0 que decorre que o setor educacional privado em constante processo de expansão chama a atenção política nos interesses econômicos.

Em acréscimo, essa processualidade vem engendrando uma oligopolização do mercado educacional, logo, com base nos dados expostos por Sguissardi (2015), se nos detivermos apenas a Kroton que incorpora a Anhanguera, já estará detendo aproximadamente $20 \%$ das matrículas do ensino superior privado, ao passo que, se lançarmos olhos para os 12 maiores grupos educacionais de cerca de 2 mil IPES, esse percentual é acrescido para cerca de $40 \%$, total, que correspondia, em 2012, cerca de $73 \%$ das matrículas nas IES públicas e privadas.

Tabela 5 - Os 12 maiores grupos educacionais privado-mercantis - 2013 - (Brasil)

\begin{tabular}{c|c|c|c|c}
\hline Ordem & Grupo/Instituição & $\begin{array}{c}\text { Receita líquida } \\
\text { em R\$ milhões }\end{array}$ & $\begin{array}{c}\text { Número de } \\
\text { alunos }\end{array}$ & Mercado \\
\hline $1^{\circ}$. & Kroton & 2.015 & 519.000 & 9,5 \\
\hline $2^{\circ}$. & Anhanguera & 1.812 & 442.000 & 8,1 \\
\hline $3^{\circ}$. & Estácio & 1.731 & 315.700 & 5,8 \\
\hline $4^{\circ}$. & Unip & 1.431 & 247.520 & 4,5 \\
\hline $5^{\circ}$. & Laureate & 1.115 & 170.000 & 3,1 \\
\hline $6^{\circ}$. & Uninove & 584 & 134.000 & 2,5 \\
\hline $7^{\circ}$. & Unicsul & 529 & 55.000 & 1 \\
\hline $8^{\circ}$. & Anima & 461 & 49.000 & 0,9 \\
\hline $9^{\circ}$. & Ser Educacional & 457 & 98,8 & 1,8 \\
\hline $10^{\circ}$. & Whitney & 343 & 40.000 & 0,7 \\
\hline $11^{\circ}$. & Devry & 242 & 30.000 & 0,6 \\
\hline $12^{\circ}$. & Tiradentes & 236 & 40,7 & 0,7 \\
\hline \multicolumn{2}{r|}{ Subtotal } & 10.956 & 2.141 .720 & 39,3 \\
\hline \multicolumn{2}{r|}{ Total do Setor Privado } & 32.040 & 5.448 .730 & 100 \\
\hline
\end{tabular}

Fonte: Sguissardi (2015, p. 875) 
A partir dos dados expostos na Tabela 5, fica clara a tamanha força que o novo modo de organização do mercado da educação superior possui. No dia 2 de junho do presente ano, a revista Valor Econômico (2016) informou que as ações da Kroton ON tinham obtido alta de $13,55 \%$ e da Estácio Participações apresentou alta de $23,73 \%$, além de divulgarem que a Kroton informou à Comissão de Valores Mobiliários (CMV) que está estudando uma combinação de negócios com sua concorrente. Esse fato não foi bem recebido pelo ministro da educação do governo de Michel Temer, Mendonça Filho, o ministro estaria insatisfeito e, inclusive, pensando em até acionar o ConseIho Administrativo de Defesa Econômica em função da suposta concentração excessiva de mercado, esse fato possibilita constatar o forte vínculo que Mendonça Filho possui com a Ser Educacional. Além disso, em julho de 2016, a Kroton acertou a compra da Estácio, na qual a Ser Educacional possuía grandes interesses em sua aquisição. Contudo, a Kroton saiu na frente firmando a compra da Estácio no valor da ordem de $\mathrm{R} \$ 5,5$ bilhões, tornando-se, portanto, a maior empresa de venda de serviços educacionais do mundo.

No limite, é nítida a forte concentração do poder das IPES com fins lucrativos no movimento de suas transações no mercado de ações, além de sua forte concentração de matrículas no campo geral do ensino superior privado. A opinião pública mostra-se parcial, no que toca sua preocupação com os interesses particulares de determinada empresa educacional. A educação-mercadoria apresenta-se no bojo da concorrência pela extração lucrativa do ensino superior como nicho de mercado altamente rentável para os empresários da educação. O sentido social da educação é reduzido aos anseios lucrativos do capital.

\section{À GUISA DE CONSIDERAçõES FINAIS}

As análises realizadas no presente trabalho demonstram que, especialmente pós-LDB, a dinâmica em processo na mercadorização da educação superior tem contribuído significativamente para o setor privado-mer- cantil. Doravante as orientações dos organismos internacionais para a educação superior da periferia e semiperiferia capitalista preconizam a necessidade da diversificação institucional, bem como, das fontes de custeio, diluindo, desse modo, as fronteiras entre o público e o privado. A despeito de políticas focalizadas para as camadas populares como o ProUni e o Fies, em verdade, foi orquestrado meticulosamente todo um aparato político-jurídico e seus respectivos mecanismos para pôr em operacionalidade a racionalidade privada-mercantil do ensino superior no Brasil.

Com os Censos da Educação Superior divulgados pelo MEC é possível constatar a predominância das IPES, além da concentração de matrículas nelas, percentual de $72,82 \%$ juntando IES públicas e privadas. Essa lógica possibilitou consolidar a categoria preconizada por Rodrigues (2007), educação-mercadoria, logo, os interesses lucrativos estão em primeiro plano deixando à margem a educação pública estatal.

A configuração hodierna da educação superior denota duas tendências cruciais: i) a concentração de capitais, isto é, constituição de oligopólios educacionais geridos por fundos de investimentos nacionais e transnacionais e ii) as empresas educacionais deixaram de ser de natureza familiar para serem grupos controlados pelo capital financeiro. Essa lógica da financeirização do ensino superior está localizada na dinâmica mais ampla do capital mundializado. Harvey (2008) explicita a contínua liberdade dos limites e obstáculos regulatórios que restringiam o campo de ação da financeirização. Contudo, nessa nova configuração, a atividade financeira ocupa todos os espaços sociais. A partir dessa liberdade da financeirização sua inserção no setor educacional brasileiro é factível, "fazendo com que sua ação seja o polo dinamizador do setor, tornando-se, assim, hegemônico face aos capitais tradicionais da área" (OLIVEIRA, 2009, p. 754).

No limite, o presente trabalho não pretende encerrar esta temática, em verdade, apenas contribuir para o debate no tocan- 
te à mercadorização da educação superior. Quando a educação é convertida em mercadoria, pressupõe-se a redução da natureza social imbuída nela. Assim, empreender uma análise desse processo trata-se de uma tarefa central para os educadores, logo, é preciso verificar os limites do alcance das políticas educacionais brasileira, e quando estas se mostram totalmente em oposição com o processo educativo. Com efeito, nos setores organizados, no que se refere aos movimentos sociais, de categorias profissionais, dos educadores brasileiros e estudantil, faz-se necessário rever formas de enfrentar o movimento do mercado educacional que vai em detrimento dos interesses populares, decorrendo, assim, no desmonte da universidade pública estatal socialmente referenciada.

\section{REFERÊNCIAS}

BANCO MUNDIAL. Educação superior: as lições da experiência. 1994. Disponível em: <http:// siteresources.worldbank.org/EDUCATION/Resources/278200 -1099079877269/5476641099079956815 /HigherEd_lessons_En.pdf>. Acesso em: 11 jun. 2016.

BANCO MUNDIAL. Relatório sobre o desenvolvimento mundial. O Estado em um mundo em transformação. 1997. Disponível em: <http://bancomundial.org.brndex.phpçontent/view_folder4.html>. Acesso em: 27 jun. 2016.

BARRETO, R. G.; LEHER, R. Do discurso e das condicionalidades do Banco Mundial, a educação superior "emerge” terciária. Revista Brasileira de Educação (Impresso), v. 13, p. 423-436, 2008. BITTAR, M.; OLIVEIRA, J. F.; MOROSINI, M. (Orgs.). Educação superior no Brasil - 10 anos pós-LDB. Brasília: Instituto Nacional de Estudos e Pesquisas Educacionais Anísio Teixeira, 2008.

BRASIL. Ministério da Educação. Instituto Nacional de Pesquisas Educacionais Anízio Teixeira. Censo da Educação Superior (2010). Brasília, DF: INEP, 2010. Disponível em: <http://download. inep.gov.br/educacao_superior/censo_superior/documentos/2010/divulgacao_censo_2010. pdf $>$. Acesso em: 10 mar. 2016.

. Ministério da Educação. Instituto Nacional de Pesquisas Educacionais Anísio Teixeira. Censo da Educação Superior (2014). Brasília, DF: INEP, 2014. Disponível em: <http://portal.inep. gov.br/visualizar/-lasset_publisher/6AhJ/content/divulgados-sinopse-e-microdados-do-censo-de-2014?redirect=http\%3a\%2f\%2fportal.inep.gov.br\%2fhome>. Acesso em: 13 mar. 2016.

BRESSER PEREIRA, L. C. Estratégia e estrutura para um novo Estado. Revista de Economia Política, v. 17, n. 3: 24-38, jul./set. de 1997.

CARTA DE PORTO ALEGRE. III Cumbre Ibero-americana de Reitores de Universidades Públicas, 25-27 de abril. 2002.

CARVALHO, C. H. A. A mercantilização da educação superior brasileira e as estratégias de mercado das instituições lucrativas. Revista Brasileira de Educação, v. 18, n. 54, 2013, p. 761-801.

CARVALHO, C. H. A. Política para o ensino superior no Brasil (1995-2006): ruptura e continuidade nas relações entre público e privado. XXIX Encontro Anual da ANPED, Caxambu, 2006.

CATANI, A. M.; OLIVEIRA, J. F. A Reestruturação da Educação Superior no Debate Internacional: a padronização das políticas de diversificação e diferenciação. Universidade e Sociedade. Brasília, v. 10, n. 21, p. 92-101, 2000.

CHAVES, V. L. J. Política de financiamento e a expansão da educação superior no Brasil: o público e o privado em questão. ETD. Educação Temática Digital, v. 17, p. 427-441, 2015.

CHAVES, V. L. J.; SILVA JÚNIOR, J. R.; CATANI, A. M. A Universidade brasileira e o PNE: instrumentalização e mercantilização educacionais. São Paulo: Editora Xamã, 2013. 
CHAVES, V. L. J. A política para a educação superior: entre o público e o privado. In: 28a. Reunião Anual da ANPED, 2005, Caxambu/MG. Disponível em: <http://www.anped.org.br/reunioes/26/trabalhos/veraluciachaves.pdf>. Acesso em: 11 jul. 2016.

CHAVES, V. L. J. Expansão da privatização/mercantilização do ensino superior brasileiro? a formação de oligopólios. Educação \& Sociedade (Impresso), v. 31, p. 481-500, 2010.

CHAVES, V. L. J.; AMARAL, N. C. A educação superior no Brasil: os desafios da expansão e do financiamento e comparações com outros países. Revista Educação em Questão (On-line), v. 51, p. 95-120, 2015. Disponível em: <https://periodicos.ufrn.br/educacaoemquestao/article/viewFile/7173/5299>. Acesso em: 21 jul. 2016.

DALE, R. Globalização e Educação: demonstrando a existência de uma "Cultura Educacional Mundial Comum" ou localizando uma "Agenda Globalmente Estruturada para a Educação"? Educação e Sociedade, Campinas, v. 25, n. 87, p. 423-460, mai./ago. 2004.

ENGELS, F. A ideologia Alemã. São Paulo: Ática, 1981.

. A origem da família, da propriedade privada e do Estado, 2. ed. Rio de Janeiro: Vitória, 1964.

FOLHA DE S. PAULO. MEC quer criar controle do Prouni, 21 set. 2004. Disponível em: < http:// www1.folha.uol.com.br/folha/educacao/ult305u16079.shtml>. Acesso em: 11 jan. 2016.

FRAUCHES, C. C. LDB Anotada e Legislação Complementar. Marília: Consultoria de Administração, 2000.

LEHER, R.; SOUSA, P. H. Financeirização no ensino superior privado e o estado capitalista: alguns elementos para discussão. In: VII Encontro Brasileiro de Educação e Marxismo. 2016.

LIMA, K. O Banco Mundial e a educação superior brasileira na primeira década do novo século. Revista Katálysis (Impresso), v. 14, p. 86-94, 2011.

MARX, K.; ENGELS, F. O manifesto do partido comunista. São Paulo: Expressão Popular, 2010. MÉSZÁROS, I. Para além do capital. São Paulo: Editorial Boitempo, 2002.

MINTO, L. W. As reformas do ensino superior no Brasil: o público e o privado em questão. Campinas: Autores Associados, 2006.

OLIVEIRA, Romualdo Portela de. A transformação da educação em mercadoria. Educação \& Sociedade (Campinas), v. 30, n. 108, p. 739-760, 2009.

OTRANTO, C. R. A Reforma da Educação Superior do Governo Lula: da inspiração à implantação. In: SILVA JR, J. R.; OLIVEIRA, J. F.; MANCEBO, D. (Org.). Reforma Universitária: dimensões e perspectivas. 1ed.Campinas, SP: Alínea, 2006, v. 1, p. 43-58.

QUEIROZ, V. Fundo de Financiamento Estudantil (FIES). Universidade e Sociedade (Brasília), v. 45, p. 44-57, 2015.

REIS, L. F. Dívida Pública, Política Econômica e o financiamento das universidades federais nos governos Lula e Dilma (2003-2014). Universidade e Sociedade (Brasília), v. 57, p. 16- 35, 2016.

RISTOFF, D. Educação superior - 10 ano pós-LDB: da expansão à democratização. In: BITTAR, M.; OLIVEIRA, J. F.; MOROSINI, M. (Orgs.). Educação superior no Brasil - 10 anos pós-LDB. Brasília: Instituto Nacional de Estudos e Pesquisas Educacionais Anísio Teixeira, 2008, p. 39-50.

RODRIGUES, J. Os empresários e a educação superior. Campinas: Autores Associados, 2007.

SADER, E. Público versus mercantil. In: Folha de São Paulo. 19 de junho. 2003.

SECRETARIA DA RECEITA FEDERAL. Demonstrativo dos Gastos Governamentais Indiretos de Natureza Tributária - (Gastos Tributários) - PLOA 2014. Disponível em: <http://idg.receita. fazenda.gov.br/dadoseceitadada/gastos-tributarios/previsoes-ploa/arquivos-e-imagens/dgt2014>. Acesso em: 12 jan. 2016. 
SGUISSARDI, V. Universidade pública estatal: entre o público e o privado/mercantil. In: Universidad e Investigación científica. Vessuri, Hebe. CLACSO, Consejo Latinoamericano de Ciencias Sociales, Buenos Aires. Noviebre, 2006, p. 103-133.

SGUISSARDI, V. Educação Superior no limiar do novo século. Traços internacionais e marcas domésticas. In: em Zainko, M. A. e Gisi, M. L. (Orgs.). Políticas e gestão da educação superior. Curitiba: Champagnat/Insular. 2003, p. 117-141.

SGUISSARDI, V. Modelo de expansão de educação superior no Brasil: predomínio privado/mercantil e desafios para a regulação e a formação universitária. Educação e Sociedade, v. 29/105, p. 991-1.022, 2008.

SGUISSARDI, Valdemar. Educação Superior no Brasil. Democratização ou massificação mercantil? Educ. Soc., Campinas, v. 36, n. 133, p. 867-889, dez. 2015. Disponível em: <http://www.scielo.br/scielo.php?script=sci_arttext\&pid=S0101-73302015000400867\&lng=pt\&nrm=iso >. Acesso em: 26 jul. 2016.

SILVA JÚNIOR, J. R.; FERREIRA, L. R.; KATO, F. B. G. Trabalho do professor pesquisador diante da expansão da pós-graduação no Brasil pós-LDB. Revista Brasileira de Educação (Impresso), v. 18, p. 435-456, 2013.

SILVA JÚNIOR, J. R.; SGUISSARDI, V. As novas faces da educação superior no Brasil: reforma do Estado e mudança na produção. São Paulo: Cortez, 2001.

VILA, S. F. O.; LÉDA, D. B.; VALE, A. A. Configurações do setor privado-mercantil na expansão da educação superior privada: notas para a análise do trabalho docente. MANCEBO, D.; SILVA JR, J. R. (Orgs.). Trabalho docente e expansão da educação superior brasileira. Rio de Janeiro: EDUERJ, 2012.

\section{DADOS DOS AUTORES}

\section{Kátia Regina Rodrigues Lima}

Mestre em Educação pelo Programa de Pós-graduação em Educação pela Universidade Federal do Ceará. Professor do departamento de Educação Física das Faculdades INTA (Instituto Superior de Teologia Aplicada). Ceará - Brasil. alisson.slider@yahoo.com

\section{Frederico Jorge Ferreira Costa}

Doutora em Educação pela Universidade Federal de São Carlos. Professora do Programa de Pós-Graduação em Educação da Universidade Federal Ceará. Professora da Universidade Regional do Cariri. Ceará - Brasil. kareli20042004@yahoo.com

\section{Emmanoel Lima Ferreira}

Doutor em Educação pela Universidade Federal do Ceará. Professor na Faculdade de Educação de Itapipoca da Universidade Estadual do Ceará, pesquisador colaborador do Instituto de Estudos e Pesquisas do Movimento Operário. Ceará - Brasil. frederic01917@yahoo.com

\section{Alisson Slider do Nascimento de Paula}

Doutor em Sociologia pela Universidade Federal do Ceará. Professor da Universidade Regional do Cariri. Ceará - Brasil. emmanoellima@yahoo.com

Submetido em: 26-8-2016

Aceito em: 8-3-2017 